against any profit being made by donors, arguing that such payments should be banned by law (subject only to the proper cost of recovering and processing tissue being recoverable by reputable suppliers of human tissue). As to indemnification of living donors, it would go no further than payments to cover out-of-pocket expenses, loss of income, and subsequent sickness.

The publicity which the commission's activities attracted in the course of preparing and publishing its report did a lot in Australia to remedy the ignorance of the public and apathy of the medical profession towards this important subject. Of particular interest is its warning that the difficulties and distress experienced by medical staff in dealing with dying patients are likely to increase rather than diminish as medical advances add to the patient's prospect of survival, and the report concluded: "Careful instruction and precept in medical ethics and behaviour and related subjects are in the commission's views likely to benefit both the student and the community. The deans of medical faculties throughout Australia are invited to consider the adequacy of the present curricula." Notwithstanding similar evidence given to the Royal Commission on Medical Education" some years ago by several important bodies in Britain, that report contained no reference whatsoever to medical ethics.

1 Law Reform Commission, Report No. 7, Human Tissuc Transplants. Canberra, Australian Government Publishing Service, 1977.

- British Medical fournal, 1978, 1, 120.

${ }^{3}$ British Medical fournal, 1976, 2, 1187.

4 British Medical Fournal, 1974, 2, 344.

5 Roval Commission on Medical Education, 1965-8, Report, Cmnd 3569 London, HMSO, 1968.

\section{Prevention and treatment of retinal detachment}

Critics of high technology medicine who question its ability to add to the sum total of human happiness should perhaps look at the successes of treatment for retinal detachment.

Detachment of the retina is a common problem for ophthalmologists, affecting as it does about one in every 20000 of the population each year. ${ }^{1}$ By far the most common type of detachment is that associated with retinal hole formation-rhegmatogenous detachment-and certain highrisk groups can be identified. These include shortsighted people and patients who have had their cataracts removed. People with myopia of over $-10 \mathrm{D}$ run 45 times the normal risk of retinal detachment, ${ }^{1}$ and among aphakic patients the incidence is about $2^{\circ}, .^{2}$ This type of detachment responds favourably to prophylactic treatment and to surgery. Exudative detachments occur as a secondary phenomenon associated, for example, with acute systemic hypertension and with ocular vascular or malignant tumours; their management depends on treating the precipitating condition. The third type of retinal detachment is associated with traction from fibrous tissue developing within the eye and the related vitreous stress. This type of detachment is common in patients with advanced diabetic retinopathy and may also be caused by direct trauma; again it is becoming increasingly amenable to treatment by modern techniques. ${ }^{3}$

The natural history of rhegmatogenous detachments is disastrous. ${ }^{4}$ The retina invariably becomes totally detached, and the eye loses all vision. It was Gonin who first realised the significance of the retinal hole, and all surgery of retinal detachment is based on his principle of finding and closing the hole so that the retina may flatten. Success in retinal surgery depends, therefore, not only on surgical skill and judgment but also on expert ophthalmoscopy. Centres specialising in retinal detachment surgery now claim $80-90^{\circ}{ }_{0}$, success rates in 3 anatomical reattachment of the retina in this type of lesion. $\stackrel{1}{2}$ Furthermore, the fact that retinal holes are the precursors of. retinal detachment allows a logical approach to prophylaxis. $\overrightarrow{\bar{B}}$ All patients coming to an ophthalmic clinic for the first time $\overrightarrow{0}$ should have their pupils dilated so that the peripheral retina $\frac{\bar{O}}{}$ may be examined for flat retinal holes or weak areas. These may $\frac{\bar{m}}{\vec{T}}$ then be assessed for treatment either by photocoagulation or $\stackrel{\mathbb{Q}}{\mathcal{Q}}$ by cryotherapy. Certain groups should be examined with $\$$ special care-those who have already had a retinal detachment $\vec{\circ}$ in one eye, myopic and aphakic patients, and those who have suffered trauma to the eye. The skill required for identifying $\vec{\omega}$ retinal holes is one of the main arguments against allowing opticians to be in charge of primary ophthalmic care.

With the growing use of photocoagulation for diabetic $\overrightarrow{\dot{\sigma}}$ retinopathy, especially in the early proliferative phase, ${ }^{6}$ the $\vec{\circ}$ incidence of traction retinal detachment in diabetics should decline. At present, however, these lesions present major $\vec{\mathscr{}}$ problems to the ophthalmologist and often require surgery, 을 both to deal with the detachment and also to remove the source $N$ of traction by vitrectomy. ${ }^{3}$ Combined vitrectomy and retinal ${ }_{c}^{\infty}$ detachment surgery has also proved to be an important advance in treating ocular trauma-much of which is due to injuries from car windscreens. Here prevention ought to be possible through legislation to make the wearing of seat belts $\vec{\varphi}$ compulsory and through the general use of laminated glass windscreens.

Böhringer, H R, ()phthalmologica, 1956. 131, 331.

Scheie, $\mathrm{H}$ B, Morse, $\mathrm{P} \mathrm{H}$, and Aminlari, A, Archices of ()phthalmology, $1973, \mathbf{8 9}, 293$.

Boase, D, et al, Transactions of the (Ophthalmological Societies of the United Kingdom, 1978, 97, in press.

1 Duke-Elder, S (ed), System of Ophthalmology, vol 10. London, Kimpton, 1967.

Gonin, J, Le Décollement de la Rétine. Lausanne, Libraire Payot, 1934.

Cheng, H, et al, British .Medical fournal, 1977, 1, 739

\section{Tumours of the nose}

Nasal obstruction is a symptom that leads most people to seek 윽 medical advice with little delay. Every practitioner should be $N$ able to examine the interior of the nose, and anterior rhino- $\rightarrow$ scopy will usually confirm clinicial suspicions. The most common causes of obstruction are deviation of the nasal $\vec{N}$ septum, nasal polypi, and allergic rhinitis-all diagnosable N readily enough from the history and the fact that the obstruction is usually (but not always) bilateral. On palpation a simple o nasal polyp is soft and mobile, and does not bleed. Often its presence is obvious; but long-standing nasal polypi may present in the anterior nares, where the exposed surface can $\frac{0}{0}$ become thickened and vascular, making the polyp difficult to $\overrightarrow{\mathbb{D}}$ distinguish from a tumour without biopsy.

In fact, innocent tumours are not common. Most of those $\frac{\varrho}{0}$ that do occur are squamous papillomas, transitional cell papillomas, or haemangiomas; neurofibromas, keratoacanth- 응 omas, and chondromas are rarities, as are the intranasal mixed tumours (also known as pleomorphic salivary adenomas), which present special features. Malignant tumours are rare: they comprise $0.3^{\prime \prime}$ " of all cancers in England but close to $1^{\prime \prime}$ " in Africa. ${ }^{1}$ Squamous carcinoma is seen most often; malignant 